\title{
Moderate alcohol consumption alters both leucocyte gene expression profiles and circulating proteins related to immune response and lipid metabolism in men
}

\author{
Michel M. Joosten ${ }^{1,2 *}$, Marjan J. van $\operatorname{Erk}^{1}$, Linette Pellis ${ }^{1}$, Renger F. Witkamp ${ }^{2}$ and Henk F. J. Hendriks ${ }^{1}$ \\ ${ }^{1}$ Earth, Environment and Life Sciences, PO Box 360, 3700 AJ Zeist, The Netherlands \\ ${ }^{2}$ Division of Human Nutrition, Wageningen University, Wageningen, The Netherlands
}

(Submitted 14 December 2010 - Final revision received 26 September 2011 - Accepted 30 September 2011 - First published online 6 December 2011 )

\begin{abstract}
Moderate alcohol consumption has various effects on immune and inflammatory processes, which could accumulatively modulate chronic disease risk. So far, no comprehensive, integrative profiling has been performed to investigate the effects of longer-term alcohol consumption. Therefore, we studied the effects of alcohol consumption on gene expression patterns using large-scale profiling of whole-genome transcriptomics in blood cells and on a number of proteins in blood. In a randomised, open-label, cross-over trial, twenty-four young, normal-weight men consumed $100 \mathrm{ml}$ vodka $(30 \mathrm{~g}$ alcohol) with $200 \mathrm{ml}$ orange juice or only orange juice daily during dinner for 4 weeks. After each period, blood was sampled for measuring gene expression and selected proteins. Pathway analysis of 345 downregulated and 455 up-regulated genes revealed effects of alcohol consumption on various signalling responses, immune processes and lipid metabolism. Among the signalling processes, the most prominently changed was glucocorticoid receptor signalling. A network on immune response showed a down-regulated NF-кB gene expression together with increased plasma adiponectin and decreased pro-inflammatory IL-1 receptor antagonist and IL-18, and acute-phase proteins ferritin and $\alpha 1$-antitrypsin concentrations (all $P<0 \cdot 05$ ) after alcohol consumption. Furthermore, a network of gene expression changes related to lipid metabolism was observed, with a central role for PPAR $\alpha$ which was supported by increased HDL-cholesterol and several apo concentrations (all $P<0 \cdot 05$ ) after alcohol consumption. In conclusion, an integrated approach of profiling both genes and proteins in blood showed that 4 weeks of moderate alcohol consumption altered immune responses and lipid metabolism.
\end{abstract}

Key words: Alcohol consumption: Inflammation: NF-kB: Lipid metabolism: Glucocorticoid signalling

Moderate alcohol consumption has been consistently associated with a reduced risk of $\mathrm{CVD}^{(1)}$ and type 2 diabetes ${ }^{(2)}$ compared with abstention. Atherosclerosis, the underlying cause of many CVD, is increasingly understood to be a chronic, low-grade inflammatory disease of the arterial wall $^{(3)}$. Elevated levels of inflammatory markers have been associated with the risk of $\mathrm{CVD}^{(4)}$ and type 2 diabetes ${ }^{(5)}$. In addition to the improvements in lipid profile, fibrinogen and insulin sensitivity, alcohol consumption is known to modulate several immune functions and inflammatory processes $^{(6,7)}$. In observational studies, moderate alcohol consumption is indeed associated with lower levels of markers of systemic inflammation ${ }^{(8)}$ and C-reactive $\operatorname{protein}^{(9,10)}$. Data from randomised trials on inflammatory markers after prolonged moderate alcohol consumption are scarce but do suggest lower levels of certain cytokines ${ }^{(11)}$ and C-reactive protein $^{(12,13)}$, although not consistently ${ }^{(14)}$. Acute moderate alcohol consumption has been shown to suppress the production of the pluripotent NF- $\mathrm{B}$ in leucocytes ${ }^{(15,16)}$. Activation of $\mathrm{NF}-\kappa \mathrm{B}$, induced by a wide range of signals including lipopolysaccharides and viruses, is a pivotal step in the induction of several inflammatory cytokines, chemokines and growth factors.

Besides their important role in inflammatory responses and the immune system, leucocytes are also the most readily available tissue for gene expression profiling. More importantly, their gene expression profiles have previously been shown to reflect dietary-induced changes in several short-term and longer-term intervention trials ${ }^{(17,18)}$. Combining gene and protein profiling in pathway analyses highly facilitates the biological interpretation of changes induced by dietary intervention $^{(19)}$. Hence, we analysed gene expression profiles of leucocytes and several circulating proteins to examine the effect of moderate alcohol consumption on immune and inflammation parameters and to explore other potentially favourable metabolic effects.

Abbreviations: EtG, ethyl glucuronide; GCR, glucocorticoid receptor.

*Corresponding author: Dr M. M. Joosten, fax +31 3069449 28, email m.m.joosten@umcg.nl 


\section{Methods}

\section{Study design}

The study used a randomised, open-label, cross-over design, consisting of two 4-week periods. Subjects consumed two miniatures $(50 \mathrm{ml}$ each) of vodka (Smirnoff, Diageo, London, UK; $30 \mathrm{~g}$ alcohol, which corresponds to three Dutch standard consumption units) with $200 \mathrm{ml}$ orange juice (Appelsientje, Riedel, Ede, The Netherlands) or only orange juice daily for 4 weeks during dinner. The study was conducted at TNO (a Dutch acronym for applied scientific research), in Zeist, The Netherlands. The study was conducted according to the guidelines laid down in the Declaration of Helsinki and all procedures involving human subjects were approved by an independent centralised ethics committee (METOPP, Tilburg, The Netherlands). Written informed consent was obtained from all subjects. The study was registered at Clinicaltrials.gov (no. NCT00918918). Allocation to treatment order was randomised according to BMI and age. Blood sampling was done on the morning after 4 weeks of each treatment period, after an overnight fast. Compliance was monitored by weekly measurement of urinary ethyl glucuronide (EtG), a direct phase II metabolite of ethanol formed by the action of uridine 5'-diphospho-glucuronosyl transferase. EtG has been reported to be a superior marker with $100 \%$ sensitivity as a biomarker of recent drinking. It persists in the urine up to approximately $75-85 \mathrm{~h}$ after the last intake ${ }^{(20)}$. To assess unintentional ethanol exposure during the juice intervention for urinary EtG values, the cut-off limit was set at $>0.25 \mathrm{mg}$ / $\mathrm{ml}(1 \cdot 1 \mu \mathrm{mol} / 1$, positive sample). To measure compliance during the vodka and juice intervention, the cut-off limit was set at EtG values $<0.5 \mathrm{mg} / \mathrm{ml}(2.2 \mu \mathrm{mol} / \mathrm{l}$, negative sample). Additional measures of compliance were the increase in HDL-cholesterol after alcohol consumption ${ }^{(21)}$ and the return of empty miniatures of vodka.

\section{Subjects}

We recruited twenty-four apparently healthy, non-smoking, male subjects aged between 21 and 40 years. Subjects were eligible if they were used to consuming between 5 and 28 units of alcohol per week, were free of any medication at the beginning of the study, had a BMI between 18 and $27 \mathrm{~kg} / \mathrm{m}^{2}$ and had no family history of alcoholism. Subjects gave written informed consent and received a compensation for their participation. They were instructed to maintain their habitual body weight, food pattern and physical activity pattern, and were told to refrain from any alcoholic products during the entire study except the vodka supplied by TNO.

\section{Blood and urine handling and analysis}

Blood samples were obtained from the antecubital vein of the forearm and collected in tubes containing clot activator for serum and in ice-chilled tubes containing $\mathrm{K}_{3}$ EDTA for plasma (Vacutainer Systems; Becton Dickinson, Plymouth, UK). Blood was centrifuged for $15 \mathrm{~min}$ at $2000 \mathrm{~g}$ at $4^{\circ} \mathrm{C}$, within $15-30 \mathrm{~min}$ after collection and stored at $<-70^{\circ} \mathrm{C}$.
Serum clinical chemistry tests included the measurement of $\gamma$-glutamyltransferase, alanine aminotransferase, aspartate aminotransferase, alkaline phosphatase, glucose, insulin, TAG, NEFA, total cholesterol, HDL-cholesterol, LDL-cholesterol and phospholipids and were analysed with enzymatic techniques (Boehringer-Mannheim, Mannheim, Germany) on an Olympus AU400 clinical chemistry analyser (OlympusDiagnostica Europe, Hamburg, Germany). Total adiponectin was measured using MesoScale Diagnostics assays (catalogue no. K151IYC-1; Meso Scale Discovery, Gaithersburg, MD, USA). A total of six serum apo (apoA-I, apoA-II, apoB, apoC-I, apoC-III and apoE) and forty-seven plasma proteins (Human InflammationMAP ${ }^{\mathrm{TM}}$ 1.0; Rules-Based Medicine, Austin, TX, USA; http://www.rulesbasedmedicine.com/products-services/ Human-InflammationMAP.asp) were analysed using a beadbased multiplexed immunoassay at the biomarker-testing laboratory Rules-Based Medicine (Austin, TX, USA). The socalled $80 \%$ rule was applied to the multiplex protein dataset to retain only those plasma analytes for which $\geq 80 \%$ of the values were above the detection limit for $\geq 1$ of the two treatment groups ${ }^{(22)}$, resulting in the retention of twenty-nine of the forty-seven antigens measured in plasma. Values below the detection limit that remained in the truncated dataset were replaced by a value of half of the detection limit. Values for the remaining samples that were not measurable on the standard curve for a specific protein were set at $0 \cdot 1$ times the detection limit for that protein. For gene expression analysis, $2.5 \mathrm{ml}$ blood were collected in PAXgene tubes (Becton Dickinson, Erembodegem, Belgium) and stored according to the manufacturer's instructions. EtG was determined in morning urine samples as described previously ${ }^{(23)}$.

\section{RNA extraction, labelling and hybridisation}

Microarray hybridisation was performed on RNA extracted from the whole blood, which was collected at the end of each 4-week intervention period. RNA was isolated using the PAXgene Blood RNA Kit (Qiagen, Venlo, The Netherlands), according to the manufacturer's instructions. Quality control, RNA labelling and hybridisation were performed at ServiceXS (Leiden, The Netherlands). RNA concentration was measured using a Nanodrop ND-1000 spectrophotometer (Nanodrop Technologies, Wilmington, DE, USA). RNA quality and integrity was determined using Lab-on-Chip analysis on an Agilent 2100 Bioanalyzer (Agilent Technologies, Inc., Santa Clara, CA, USA). Average RNA yield of the samples was $10 \cdot 3 \mu \mathrm{g}$ (range $1.9-28 \mu \mathrm{g}$ ) and the average RNA integrity number score was 8.9 (range 6.8-9.6). The labelling reaction included a globin reduction step. To block the $3^{\prime}$ ends of globin transcripts, four different peptide nucleic acids were used. Due to the addition of the globin peptide nucleic acids sequences to the labelling reaction, the labelling of globin transcripts is hampered in favour of the other transcripts, which are typically under-represented in blood cells. As a consequence, the signal strength of non-globin genes is much higher after globin reduction. Biotinylated complementary RNA was prepared using the Illumina TotalPrep RNA Amplification Kit (Ambion, Inc., Austin, TX, USA), according 
to the manufacturer's specifications starting with $500 \mathrm{ng}$ total RNA. For each sample, $750 \mathrm{ng}$ complementary RNA was used to hybridise to the Sentrix HumanHT-12 v3 Expression BeadChips (Illumina, Inc., San Diego, CA, USA). Each BeadChip contains twelve arrays. Hybridisation and washing were performed according to the Illumina standard assay procedure. Scanning was performed on the Illumina iScanner (Illumina, Inc.). Image analysis and the extraction of raw expression data were performed using Illumina Genomestudio 2010 Gene Expression software (Illumina, Inc., San Diego, CA, USA) with background subtraction and no normalisation. All forty-eight arrays passed the quality-control criteria. Probe-level data (48803 probes) were subjected to quantile normalisation in GeneSpring GX 11.0 (Agilent Technologies, Santa Clara, CA, USA). Of these, 19378 probes were expressed in at least one sample in the present study (filtering on a detection $P$ value $>0.99$ in at least one sample). This set of probes was used for further analysis. Gene expression data are available in the National Center for Biotechnology Information (NCBI) Gene Expression Omnibus (http://www.ncbi.nlm.nih.gov/geo/).

\section{Statistical analysis}

Serum and plasma markers with a skewed distribution were transformed to their natural logarithm for analyses. We used a mixed-model ANOVA (PROC Mixed procedure in SAS (SAS Institute, Cary, NC, USA)) that included terms for treatment (vodka and juice $v$. juice), period (first $v$. second), main effects and the interaction between period and treatment (indicating possible carry-over effects) to compare variables between the treatments. No significant $(P>0.05)$ carry-over effects as assessed by an interaction between treatment and period effect were observed for any plasma or serum measures. Statistical analyses were performed using the SAS statistical software package (SAS version 8.2 and 9.1; SAS Institute). Statistical significance was defined as $P<0 \cdot 05$.

For gene expression data, statistical significance $(P<0.05)$ in a paired $t$ test was combined with an additional requirement of either up-regulation in fifteen or more subjects or downregulation in fifteen or more subjects. The cut-off of fifteen subjects was based on the average number of subjects who showed intervention-induced up- or down-regulation in significantly changed circulating proteins. The number of the remaining genes was further reduced by only interpreting genes that were part of enriched pathways (see the Biological interpretation section).

\section{Biological interpretation}

Functional analysis of the gene expression data was performed by using Ingenuity Pathway Analysis version 8.7 (Ingenuity Systems, Inc., Redwood City, CA, USA), identifying significantly enriched pathways and gene lists $(P<0.05)$. Networks of significantly changed genes and proteins were

Table 1. Overview of differentially expressed pathways and number of genes changed based on Ingenuity Pathway Analysis (Ingenuity Systems, Inc., Redwood City, CA, USA), ranked on most significantly changed pathway in functional group

\begin{tabular}{|c|c|c|c|}
\hline Functional group & Pathways/lists & $P$ & Changed genes $(n)^{*}$ \\
\hline \multirow[t]{10}{*}{ Signalling } & Glucocorticoid receptor signalling & 0.0017 & 21 \\
\hline & Acute myeloid leukaemia signalling & 0.0047 & 9 \\
\hline & Oestrogen receptor signalling & 0.0151 & 10 \\
\hline & Chronic myeloid leukaemia signalling & 0.0158 & 9 \\
\hline & PI3K/AKT signalling & 0.0204 & 10 \\
\hline & Neuregulin signalling & 0.0288 & 8 \\
\hline & BMP signalling pathway & 0.0324 & 7 \\
\hline & GNRH signalling & 0.0347 & 10 \\
\hline & G Beta gamma signalling & 0.0372 & 8 \\
\hline & Androgen signalling & 0.0417 & 9 \\
\hline \multirow{10}{*}{ Immune response } & Antigen presentation pathway & 0.0028 & 6 \\
\hline & Crosstalk between dendritic cells and natural killer cells & 0.0044 & 10 \\
\hline & Leucocyte extravasation signalling & 0.0095 & 15 \\
\hline & Oncostatin M signalling & 0.0135 & 5 \\
\hline & PKC $\theta$, signalling in T-lymphocytes & 0.0151 & 10 \\
\hline & GM-CSF signalling & 0.0155 & 7 \\
\hline & B-cell receptor signalling & 0.0166 & 12 \\
\hline & IL-15 signalling & 0.0407 & 6 \\
\hline & T-cell receptor signalling & 0.0457 & 8 \\
\hline & Role of NFAT in the regulation of the immune response & 0.0468 & 12 \\
\hline \multirow[t]{3}{*}{ Lipid metabolism/metabolism } & Mechanism of gene regulation by peroxisome proliferators via PPAR $\alpha$ & 0.0065 & 10 \\
\hline & Citrate cycle & 0.0069 & 5 \\
\hline & PPAR $\alpha / R X R$ activation & 0.0257 & 12 \\
\hline \multirow[t]{2}{*}{ Miscellaneous/other } & Role of NFAT in cardiac hypertrophy & 0.0178 & 14 \\
\hline & Selenoamino acid metabolism & 0.0214 & 5 \\
\hline \multirow[t]{3}{*}{ Apoptosis } & Apoptosis signalling & 0.0224 & 8 \\
\hline & Pro-apoptosis & 0.0316 & 5 \\
\hline & TNF-R1 signalling & 0.0479 & 5 \\
\hline
\end{tabular}

PI3K, phosphatidylinositol 3-kinase; AKT, serine/threonine kinase (protein kinase B); BMP, bone morphometric proteins; GNRH, gonadotrophin-releasing hormone; PKCO, protein kinase C theta; GM-CSF, granulocyte-macrophage colony-stimulating factor; NFAT, nuclear factor of activated T-cells; RXR, retinoid X receptor. ${ }^{*}$ Changed genes selected by statistical significance $(P<0.05)$ in a paired $t$ test combined with an additional requirement of either up-regulation in fifteen or more subjects or down-regulation in fifteen or more subjects. 
Table 2. Overview of circulating proteins and metabolites that significantly differed $(P<0.05)$ between the two 4-week treatments in twenty-four young men and sampled after an overnight fast (Mean values with their standard errors)

\begin{tabular}{|c|c|c|c|c|c|c|}
\hline & \multicolumn{2}{|c|}{ Orange juice } & \multicolumn{2}{|c|}{$\begin{array}{l}\text { Vodka and } \\
\text { orange juice }\end{array}$} & \multirow[b]{2}{*}{ Percentage change } & \multirow[b]{2}{*}{$P^{*}$} \\
\hline & Mean & SE & Mean & SE & & \\
\hline \multicolumn{7}{|l|}{ Inflammatory markers } \\
\hline Total adiponectin $(\mu \mathrm{g} / \mathrm{ml})$ & $10 \cdot 5$ & 0.9 & $11 \cdot 8$ & 0.9 & $8 \cdot 6$ & $<0.01$ \\
\hline $\mathrm{IL}-1$ receptor agonist $(\mathrm{pg} / \mathrm{ml})$ & 68 & 5 & 52 & 5 & $-13 \cdot 8$ & $<0.01$ \\
\hline $\mathrm{IL}-18(\mathrm{pg} / \mathrm{ml})$ & 152 & 13 & 143 & 13 & -4.0 & 0.03 \\
\hline \multicolumn{7}{|l|}{ Lipoproteins } \\
\hline HDL-cholesterol (mmol/l) & $1 \cdot 12$ & 0.04 & 1.22 & 0.05 & $8 \cdot 8$ & $<0.001$ \\
\hline Phospholipids (mmol/l) & $2 \cdot 36$ & 0.08 & $2 \cdot 52$ & 0.08 & $6 \cdot 0$ & $<0.001$ \\
\hline ApoA-II $(\mu \mathrm{mol} / \mathrm{l})$ & $12 \cdot 7$ & $0 \cdot 7$ & 13.9 & $0 \cdot 7$ & $11 \cdot 6$ & $<0.01$ \\
\hline ApoC-I ( $\mu \mathrm{mol} / \mathrm{l})$ & $7 \cdot 2$ & 0.2 & $7 \cdot 7$ & 0.2 & $7 \cdot 7$ & 0.01 \\
\hline ApoC-III $(\mu \mathrm{mol} / \mathrm{l})$ & 9.5 & 0.7 & $10 \cdot 6$ & 0.7 & $10 \cdot 4$ & 0.02 \\
\hline \multicolumn{7}{|l|}{ Miscellaneous/liver markers } \\
\hline$\gamma$-Glutamyltransferase $(\mathrm{U} / \mathrm{l})$ & $19 \cdot 8$ & 2.4 & $24 \cdot 3$ & $2 \cdot 4$ & $18 \cdot 7$ & $<0.001$ \\
\hline Ferritin $(\mathrm{ng} / \mathrm{ml})$ & 125 & 18 & 100 & 18 & $-13 \cdot 6$ & $<0.01$ \\
\hline$\alpha 1-$ Antitrypsin (mg/ml) & 1.49 & 0.05 & $1 \cdot 39$ & 0.05 & $-6 \cdot 0$ & 0.03 \\
\hline
\end{tabular}

built in MetaCore version 6.1 (GeneGo, St Joseph, MI, USA), using direct interactions or shortest path algorithm (maximum two steps and with filter for human data).

\section{Results}

\section{Subjects and compliance}

All twenty-four men who were enrolled completed the study without any serious adverse events. Mean age and BMI of the men were 25.5 (SE 3.3) years and 23.5 ( SE 2.5) kg/m². Weekly urinary EtG levels were assessed to check individual compliance to the treatments. This revealed eight positive urine samples during the orange juice-drinking period, although all $\leq 0.5 \mathrm{mg} / \mathrm{ml}$, and seven negative samples during the vodka- and juice-drinking periods out of the 192 samples analysed (overall compliance of 92\%). Another indicator for compliance was the $8.8 \%$ increase $(P<0.001)$ in HDLcholesterol after vodka and juice consumption compared with juice consumption. Data from all subjects were included in the analysis since no serious deviations in compliance to the treatments were observed.

\section{Blood (cell) analysis}

The 4 weeks of vodka and juice resulted in a down-regulation of 382 probes ( 345 genes with unique Entrez identifier) and an up-regulation of 492 probes (455 genes with unique

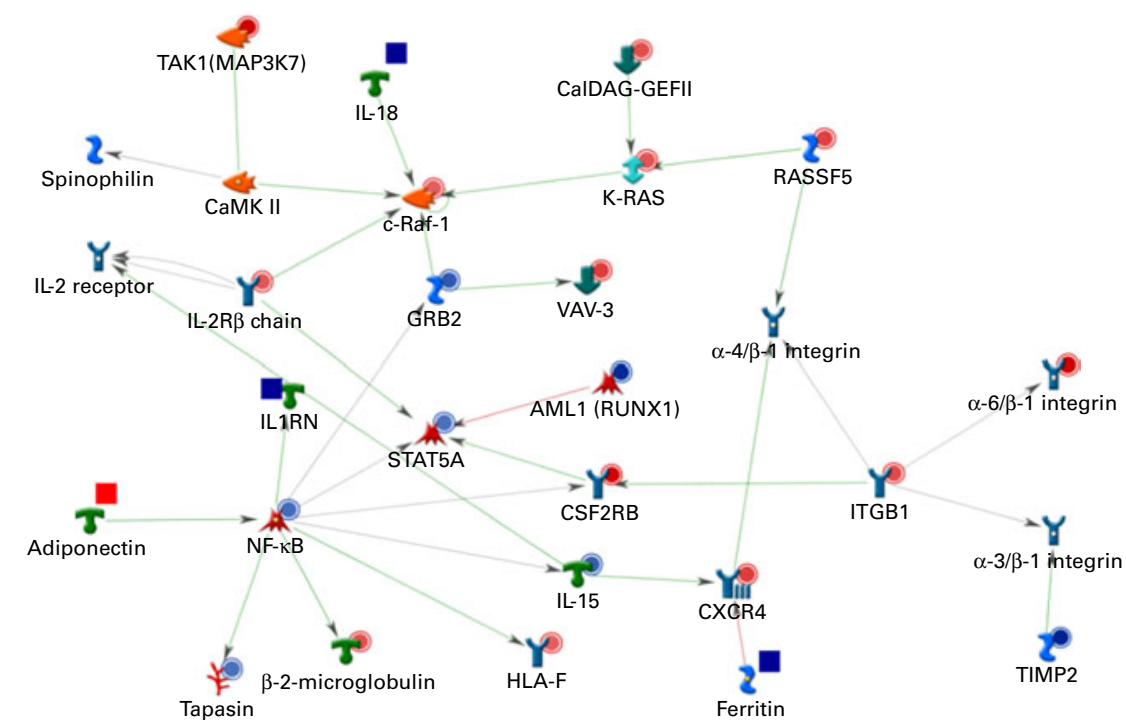

Fig. 1. Integrated network related to the functional group 'immune response' with a central role of NF- $\mathrm{B} B$. The network was derived using MetaCore (GeneGo, St Joseph, MI, USA) and based on direct interactions between significantly changed expression profiles of forty genes involved in the functional group immune response and five circulating proteins after 4 weeks of moderate alcohol consumption compared with 4 weeks of abstention. Blue indicates down-regulation in response to the alcohol intervention and red indicates up-regulation in response to the alcohol intervention. Circles, genes (measured in leucocytes); squares, plasma proteins. For expansions of gene and protein names, see Supplementary Table 1 (available at http://journals.cambridge.org/bjn). 
Entrez ID) in leucocytes ( $P<0.05$ and up- or down-regulation observed in at least fifteen subjects). To determine the biological role of these genes that were differentially expressed after vodka and juice consumption in at least fifteen subjects, we performed pathway analysis using Ingenuity Pathway Analysis (Ingenuity Systems, Inc.). Significantly enriched pathways or functional groups $(P<0.05)$ were clustered into functional groups, indicating an effect of moderate alcohol consumption on diverse signalling processes, immune response, lipid metabolism, some miscellaneous processes and apoptosis in leucocytes (Table 1).

An important functional group that was altered by the alcohol treatment compared with the control treatment was 'immune response' and consisted of pathways of antigen presentation, B- and T-cell receptor signalling and IL-15 signalling. The effect of alcohol consumption on immune function was further analysed by multiplex analysis of inflammatory plasma proteins. Plasma levels of the positive acute-phase proteins ferritin and $\alpha 1$-antitrypsin were significantly reduced as were the levels of the pro-inflammatory cytokines IL-1 receptor antagonist and IL-18 (all $P<0.05$ ), whereas plasma levels of the anti-inflammatory protein adiponectin were increased after vodka and juice consumption $(P<0.01)$ (Table 2). These proteins and the set of unique up- and down-regulated immune response genes were used for network analysis in MetaCore (GeneGo; Fig. 1). This integrative network analysis of genes and proteins revealed coherent effects of moderate alcohol consumption on immune response, as indicated by the direct links between the genes and proteins in the network. Fig. 1 depicts a central role for the transcription factor NF- $\mathrm{B}$, which was down-regulated after moderate alcohol consumption compared with abstention.

In addition, leucocyte gene expression data also indicated an effect on gene expression profiles related to lipid metabolism. Interestingly, serum HDL-concentrations and a number of other lipid-related parameters, including phospholipids and apoA-II, apoC-I and apoC-III, showed significant increases in their concentration after vodka and juice consumption $(P<0.05$; Table 2$)$. These results were integrated in a network (Fig. 2) that was generated from the set of significantly changed markers related to lipid metabolism. Again, this network approach illustrated close biological links between the alcohol-induced changes in genes and proteins involved with a central, albeit putative, role for PPAR $\alpha$.

Among the variety of signalling processes, the most prominently changed was glucocorticoid receptor (GCR) signalling with a central role for GCR $\alpha$. Fig. 3 illustrates the interactions between genes associated with glucocorticoid receptor signalling. The presence of the altered gene expression profiles of inflammatory factors such as NF- $\mathrm{B}$ and IL-8 in this pathway again indicated a link to the inflammation modulation by the alcohol intervention. The leucocyte gene expression data also indicated effects of alcohol on different

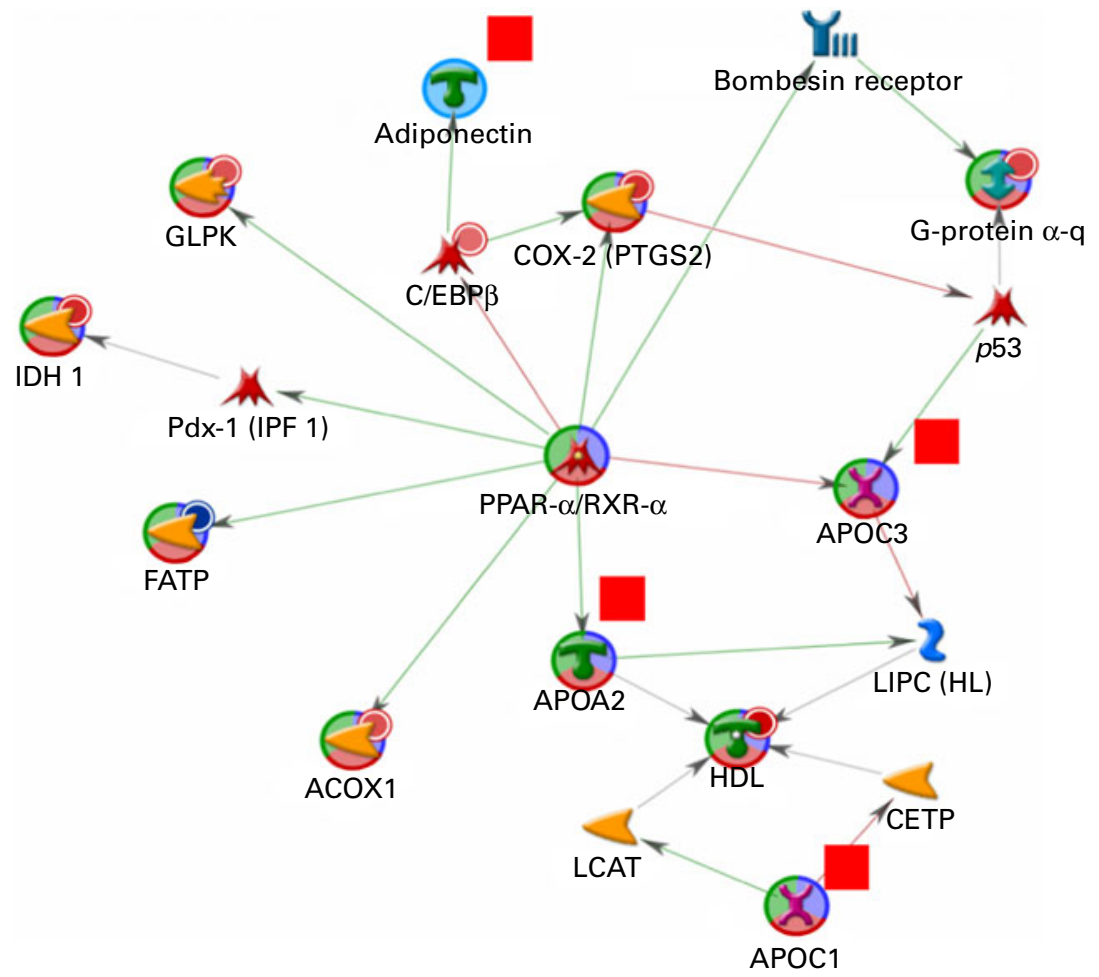

Fig. 2. Integrated network related to the functional group 'lipid metabolism' with a putative role of PPAR $\alpha$. The network was derived using MetaCore (GeneGo, St Joseph, MI, USA) and based on the shortest path algorithm (maximum two steps) between significantly changed expression profiles of eleven genes involved in PPAR-regulated pathways or citrate cycle and four circulating proteins after 4 weeks of moderate alcohol consumption compared with 4 weeks of abstention. Blue indicates down-regulation in response to the alcohol intervention and red indicates up-regulation in response to the alcohol intervention. Circles, genes (measured in leucocytes); squares, plasma proteins. For expansions of gene and protein names, see Supplementary Table 1 (available at http://journals. cambridge.org/bjn). 


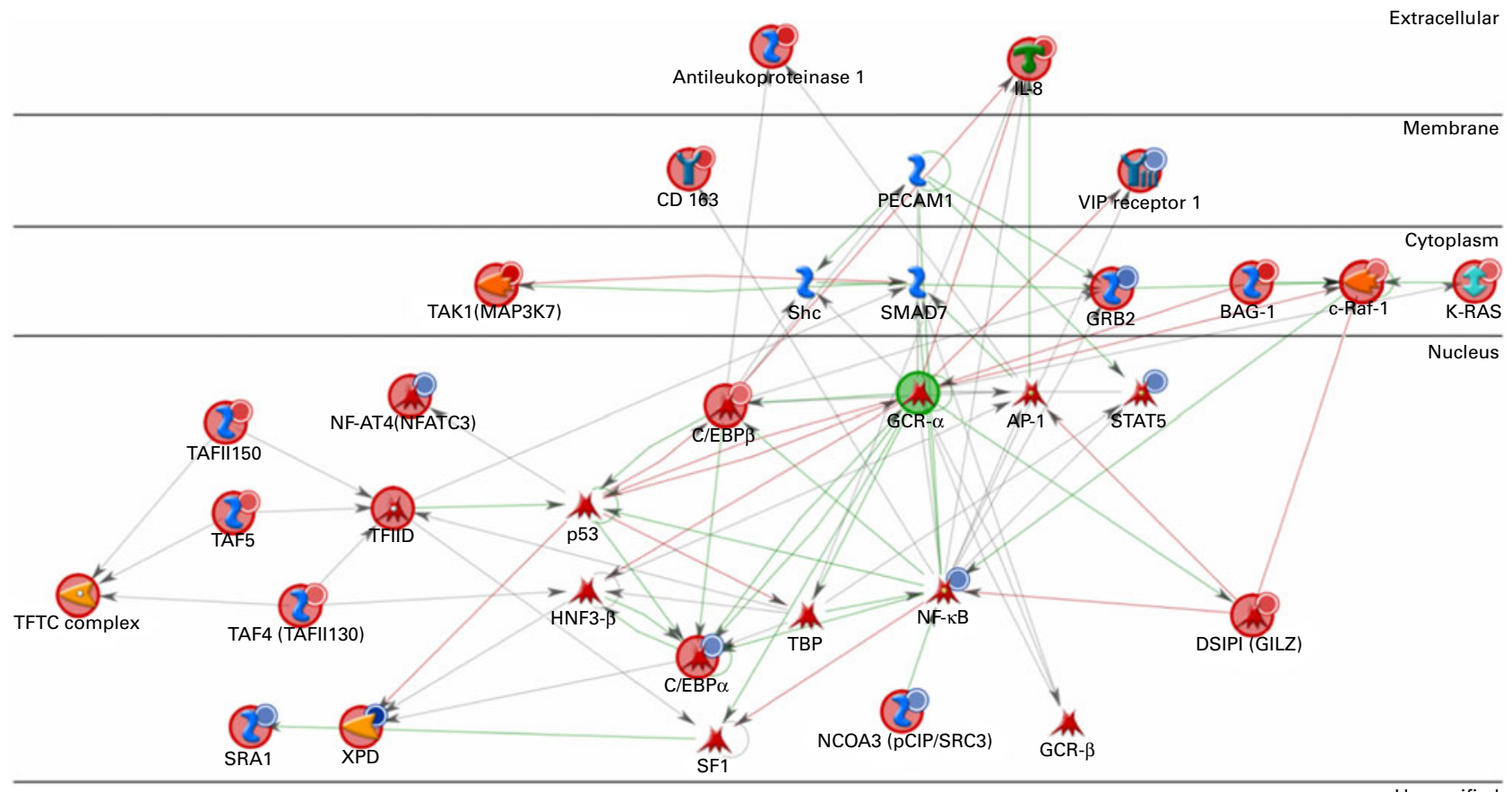

Fig. 3. Network related to glucocorticoid receptor signalling $\alpha$. The network was derived using MetaCore (GeneGo, St Joseph, MI, USA) and based on the shortest path (maximum two steps) between significantly changed expression profiles of twenty-one genes after 4 weeks of moderate alcohol consumption compared with 4 weeks of abstention. Blue circles indicate down-regulation in response to the alcohol intervention; red circles indicate up-regulation in response to the alcohol intervention. For expansions of gene and protein names, see Supplementary Table 1 (available at http://journals.cambridge.org/bjn).

other signalling processes, including pathways associated with acute and chronic myeloid leukaemia signalling and apoptosis. Since these effects were assumed not to be directly related to the processes primarily studied, they were not further analysed.

\section{Discussion}

In the present study, we jointly assessed changes in gene expression and proteins after moderate alcohol consumption in a randomised cross-over trial in young, normal-weight men. We showed that 4 weeks of moderate alcohol consumption $(30 \mathrm{~g}$ alcohol/d) resulted in leucocyte gene expression changes related to immune response, lipid metabolism, and a diverse set of signalling pathways and apoptosis. The integrated gene and protein analysis indicated that the alterations related to immune response were predominantly associated with a decreased NF- $\mathrm{BB}$ expression, whereas changes in lipid metabolism were closely associated with PPAR $\alpha$.

We observed a down-regulation of NF-кB in leucocytes after prolonged moderate vodka and juice consumption compared with consumption of juice only. The various direct connections of NF- $\mathrm{KB}$ with other immune-related gene expression and protein levels in the immune response network observed are in accordance with the pleiotropic regulatory function of $\mathrm{NF}-\kappa \mathrm{B}$ in inflammatory responses. The present findings of a down-regulated NF- $\mathrm{KB}$ expression after prolonged moderate alcohol consumption are in concord with observations ex vivo after acute alcohol administration ${ }^{(16)}$. Moreover, the network approach predicted that acute alcohol exposure prevents NF- $\mathrm{kB}$ activation, which may lead to an inhibition in pro-inflammatory cytokines such as C-reactive protein, TNF- $\alpha$ and IL-1 $\beta$ at the protein as well as the mRNA level ${ }^{(16)}$. Although these cytokines were not changed in the present study, we did observe lower levels of the positive acute-phase proteins ferritin and $\alpha 1$-antitrypsin and proinflammatory cytokines such as IL-1 receptor antagonist and IL-18 levels after moderate alcohol consumption, in line with a previous study among diabetic men ${ }^{(24)}$.

The increased total adiponectin concentrations after moderate alcohol consumption are in accordance with two observational studies ${ }^{(25,26)}$ and other clinical intervention studies among relatively young and normal-weight men ${ }^{(27)}$ and women ${ }^{(28)}$. The network analysis shows that adiponectin is directly related to both the immune response and lipid metabolic changes in response to alcohol consumption. This adds to the notion that adiponectin might be an important link between inflammation and lipid metabolism. Indeed, several lines of evidence suggest an inverse association between adiponectin and markers of inflammation ${ }^{(29)}$ and a positive association with favourable lipid profiles ${ }^{(30)}$ in observational studies. Gene expression of the adiponectin gene in leucocytes did not differ between the treatments, despite the increased protein levels after moderate alcohol consumption. However, adiponectin is predominantly expressed in adipose tissue. It has been shown that the alcohol-induced increase of the protein can largely be attributed to an increased expression of the adiponectin gene in adipose tissue ${ }^{(23)}$.

A substantial part of changes in gene expression profiles of the leucocytes found is categorised within the group designated as signalling. This group included various and divergent signalling processes. The most significantly altered and 
presumably also most relevant deduced pathway is related to glucocorticoid receptor signalling. Besides their contribution to the maintenance of basal and stress-related homeostasis in all higher organisms, glucocorticoids are part of the feedback mechanism in the immune system that turns immune activity and inflammation down. GCR $\alpha$ is known to exert these effects by down-regulating the gene expression of NF$\kappa \mathrm{B}^{(31)}$. The present reported effects of moderate alcohol consumption on inflammatory processes via GCR are thus in keeping with the existing literature and extend this by shedding light on how alcohol consumption could suppress gene expression of NF-кB and other related genes in this signalling pathway.

We found a substantial decrease in plasma ferritin concentrations after the vodka and juice treatment compared with the control treatment. Ferritin is one of the key proteins regulating $\mathrm{Fe}$ homeostasis. Growing evidence has shown that even moderately increased $\mathrm{Fe}$ stores, represented by high-normal ferritin concentrations, are associated with insulin resistance $^{(32)}$ and type 2 diabetes. The results of the present randomised trial are in contrast with observational research that shows a positive association with alcohol consumption and ferritin concentrations ${ }^{(33,34)}$. Gene expression of ferritin in the leucocytes did not change between the treatments, probably because the protein is predominantly expressed in liver tissue.

The strengths of the study are its randomised, cross-over design, the high compliance to the treatments throughout the study and the integrated approach of both gene expression profiles and proteins. However, several limitations warrant consideration. First, whole blood was collected for RNA isolation. Since globin RNA was removed from the samples, it is assumed that the remaining RNA only represented the gene expression profiles of the leucocytes. Moreover, as the leucocyte population consists of a range of cell types (e.g. lymphocytes, neutrophils, monocytes, eosinophils and basophils), we checked whether the observed changes in gene expression might be due to changes in leucocyte distribution. However, no differences between the treatments were observed in the distribution of leucocyte types (data not shown). Second, we used circulating leucocytes for gene expression profiling. Although these cells might not be representative for all tissues directly affected by alcohol consumption (e.g. liver and adipose tissue), leucocytes were chosen because of their important roles in inflammatory responses and the immune system. Furthermore, their expression profiles have previously been shown to reflect metabolic changes due to short-term and longer-term nutritional adaptation in healthy human subjects ${ }^{(18,19)}$. Third, analysis of plasma and serum proteins was not as unbiased as the gene expression analysis (whole-genome microarrays) since we predominantly measured specific proteins based on a priori expected changes in inflammatory markers and lipoproteins. We did aim to include a rather broad range of inflammatory markers by using a multiplex analysis of forty-seven inflammatory proteins and six apo. Integration of these protein data with gene expression data into networks revealed coherent effects (shown by the direct connections in both the immune response and lipid metabolism network), which underlines the close biological connection between the changes in genes and proteins due to moderate alcohol consumption. Nevertheless, although not entirely unexpected, we did not observe an association between the changes in the predominantly lipid- and liver-related protein levels and changes in the mRNA levels of the leucocytes as measured with the microarrays. Fourth, we investigated relatively young, normal-weight and non-smoking subjects who were at low risk for developing chronic diseases. Perhaps slightly overweight, middle-aged subjects would have been even more susceptible to the alcohol-induced changes. However, inflammatory markers ${ }^{(13)}$ and biological markers such as HDL-cholesterol and total adiponectin associated with diseases have previously been shown to improve after moderate alcohol consumption even in these young and relatively healthy groups ${ }^{(27,28)}$. Moreover, the association between moderate alcohol consumption and the risk of $\mathrm{CVD}^{(35)}$ and type 2 diabetes $^{(36)}$ also holds among subjects already at low risk on the basis of their multiple, favourable lifestyle behaviours.

In conclusion, a comprehensive and integrated approach of both gene and protein profiling of blood showed that moderate alcohol consumption resulted in changes in immune response and lipid metabolism. Our integrated and largescale profiling revealed potential new functional pathways and physiological mechanisms that may explain some of the health effects that moderate alcohol consumption exerts.

\section{Acknowledgements}

This study was partially supported by the European Research Advisory Board (grant no. EA 08 21), the Dutch Foundation for Alcohol Research (SAR) and the Dutch Ministry of Economic affairs. M. M. J. provided partial funding, designed the study, analysed and interpreted the data and wrote the manuscript. M. J. v. E. and L. P. participated in the data collection, analysed and interpreted the data and helped in drafting the manuscript. R. F. W. helped designing the study and critically reviewed the manuscript for important intellectual content. H. F. J. H. provided funding, designed the study and critically reviewed the manuscript for important intellectual content. All authors read and approved the final manuscript. We gratefully acknowledge the volunteers for participation; I. Klöpping, $\mathrm{H}$. Fick, D. Rouwendaal, A. Speulman, I. van den Assum, J. Jacobs, C. Hoeflaken, J. Jansen for practical work during the study; K. Toet, W. Vaes, M. von Lipzig, L. Bok and M. Rondhuis for laboratory analyses; and E. Dutman for data management. There are no conflicts of interest.

\section{References}

1. Ronksley PE, Brien SE, Turner BJ, et al. (2011) Association of alcohol consumption with selected cardiovascular disease outcomes: a systematic review and meta-analysis. BMJ 342, d671.

2. Baliunas DO, Taylor BJ, Irving H, et al. (2009) Alcohol as a risk factor for type 2 diabetes: a systematic review and meta-analysis. Diabetes Care 32, 2123-2132. 
3. Libby P, Ridker PM \& Hansson GK (2011) Progress and challenges in translating the biology of atherosclerosis. Nature 473, 317-325.

4. Pai JK, Pischon T, Ma J, et al. (2004) Inflammatory markers and the risk of coronary heart disease in men and women. $N$ Engl J Med 351, 2599-2610.

5. Pickup JC (2004) Inflammation and activated innate immunity in the pathogenesis of type 2 diabetes. Diabetes Care 27, 813-823.

6. Romeo J, Warnberg J, Nova E, et al. (2007) Moderate alcohol consumption and the immune system: a review. Br J Nutr 98, S111-S115.

7. Szabo G \& Mandrekar P (2009) A recent perspective on alcohol, immunity, and host defense. Alcohol Clin Exp Res 33, 220-232.

8. Pai JK, Hankinson SE, Thadhani R, et al. (2006) Moderate alcohol consumption and lower levels of inflammatory markers in US men and women. Atherosclerosis 186, 113-120.

9. Imhof A, Froehlich M, Brenner $\mathrm{H}$, et al. (2001) Effect of alcohol consumption on systemic markers of inflammation. Lancet 357, 763-767.

10. Albert MA, Glynn RJ \& Ridker PM (2003) Alcohol consumption and plasma concentration of C-reactive protein. Circulation 107, 443-447.

11. Romeo J, Warnberg J, Nova E, et al. (2007) Changes in the immune system after moderate beer consumption. Ann Nutr Metab 51, 359-366.

12. Sierksma A, van der Gaag MS, Kluft C, et al. (2001) Effect of moderate alcohol consumption on fibrinogen levels in healthy volunteers is discordant with effects on C-reactive protein. Ann N Y Acad Sci 936, 630-633.

13. Vazquez-Agell M, Sacanella E, Tobias E, et al. (2007) Inflammatory markers of atherosclerosis are decreased after moderate consumption of cava (sparkling wine) in men with low cardiovascular risk. J Nutr 137, 2279-2284.

14. Beulens JW, van den Berg R, Kok FJ, et al. (2008) Moderate alcohol consumption and lipoprotein-associated phospholipase A2 activity. Nutr Metab Cardiovasc Dis 18, 539-544.

15. Mandrekar P, Dolganiuc A, Bellerose G, et al. (2002) Acute alcohol inhibits the induction of nuclear regulatory factor kappa B activation through CD14/toll-like receptor 4, interleukin-1, and tumor necrosis factor receptors: a common mechanism independent of inhibitory kappa B alpha degradation? Alcohol Clin Exp Res 26, 1609-1614.

16. Mandrekar P, Catalano D, White B, et al. (2006) Moderate alcohol intake in humans attenuates monocyte inflammatory responses: inhibition of nuclear regulatory factor kappa $\mathrm{B}$ and induction of interleukin 10. Alcohol Clin Exp Res 30, 135-139.

17. van Erk MJ, Blom WA, van Ommen B, et al. (2006) Highprotein and high-carbohydrate breakfasts differentially change the transcriptome of human blood cells. Am J Clin Nutr 84, 1233-1241.

18. Bouwens M, van de Rest O, Dellschaft $\mathrm{N}$, et al. (2009) Fish-oil supplementation induces anti-inflammatory gene expression profiles in human blood mononuclear cells. Am J Clin Nutr 90, 415-424.

19. Bakker GC, van Erk MJ, Pellis L, et al. (2010) An antiinflammatory dietary mix modulates inflammation and oxidative and metabolic stress in overweight men: a nutrigenomics approach. Am J Clin Nutr 91, 1044-1059.
20. Bottcher M, Beck O \& Helander A (2008) Evaluation of a new immunoassay for urinary ethyl glucuronide testing. Alcohol Alcohol 43, 46-48.

21. Brien SE, Ronksley PE, Turner BJ, et al. (2011) Effect of alcohol consumption on biological markers associated with risk of coronary heart disease: systematic review and metaanalysis of interventional studies. BMJ 342, d636.

22. Bijlsma S, Bobeldijk I, Verheij ER, et al. (2006) Large-scale human metabolomics studies: a strategy for data (pre-) processing and validation. Anal Chem 78, 567-574.

23. Joosten MM, Beulens JW, Kersten S, et al. (2008) Moderate alcohol consumption increases insulin sensitivity and $A D I P O Q$ expression in postmenopausal women: a randomised, crossover trial. Diabetologia 51, 1375-1381.

24. Marfella R, Cacciapuoti F, Siniscalchi M, et al. (2006) Effect of moderate red wine intake on cardiac prognosis after recent acute myocardial infarction of subjects with type 2 diabetes mellitus. Diabet Med 23, 974-981.

25. Thamer C, Haap M, Fritsche A, et al. (2004) Relationship between moderate alcohol consumption and adiponectin and insulin sensitivity in a large heterogeneous population. Diabetes Care 27, 1240

26. Joosten MM, Chiuve SE, Mukamal KJ, et al. (2011) Changes in alcohol consumption and subsequent risk of type 2 diabetes in men. Diabetes 60, 74-79.

27. Beulens JW, van Loon LJ, Kok FJ, et al. (2007) The effect of moderate alcohol consumption on adiponectin oligomers and muscle oxidative capacity: a human intervention study. Diabetologia 50, 1388-1392.

28. Joosten MM, Witkamp RF \& Hendriks HF (2011) Alterations in total and high-molecular-weight adiponectin after 3 weeks of moderate alcohol consumption in premenopausal women. Metabolism 60, 1058-1063

29. Hung J, McQuillan BM, Thompson PL, et al. (2008) Circulating adiponectin levels associate with inflammatory markers, insulin resistance and metabolic syndrome independent of obesity. Int J Obes (Lond) 32, 772-779.

30. Kantartzis K, Rittig K, Balletshofer B, et al. (2006) The relationships of plasma adiponectin with a favorable lipid profile, decreased inflammation, and less ectopic fat accumulation depend on adiposity. Clin Chem 52, 1934-1942.

31. Pelaia G, Vatrella A, Cuda G, et al. (2003) Molecular mechanisms of corticosteroid actions in chronic inflammatory airway diseases. Life Sci 72, 1549-1561.

32. Wrede CE, Buettner R, Bollheimer LC, et al. (2006) Association between serum ferritin and the insulin resistance syndrome in a representative population. Eur J Endocrinol 154, 333-340.

33. Whitfield JB, Zhu G, Heath AC, et al. (2001) Effects of alcohol consumption on indices of iron stores and of iron stores on alcohol intake markers. Alcohol Clin Exp Res 25, $1037-1045$.

34. Jiang R, Manson JE, Meigs JB, et al. (2004) Body iron stores in relation to risk of type 2 diabetes in apparently healthy women. JAMA 291, 711-717.

35. Mukamal KJ, Chiuve SE \& Rimm EB (2006) Alcohol consumption and risk for coronary heart disease in men with healthy lifestyles. Arch Intern Med 166, 2145-2150.

36. Joosten MM, Grobbee DE, van der A DL, et al. (2010) Combined effect of alcohol consumption and lifestyle behaviors on risk of type 2 diabetes. Am J Clin Nutr 91, $1777-1783$. 